\title{
Visual Analysis of Construction Waste Research Based on VOSviewer
}

\author{
HAN Lihua ${ }^{1}$, GONG Zhiqi ${ }^{1,2 *}$ \\ ${ }^{1}$ School of Civil Engineering, Qinghai University,810016,Xining,Qinghai,China. \\ ${ }^{2}$ Qinghai Provincial Key Laboratory of Energy-saving Building Materials and Engineering Safety, 810016,Xining,Qinghai,China.
}

\begin{abstract}
Large-scale engineering construction projects have irreversibly damaged the ecological environment while promoting economic development and improving living standards. As the demand for realizing a resource-conscious and environment-friendly society continues to grow, people are increasingly interested in the sustainable development of construction waste. In this paper, the relevant literature in the field of construction waste is retrieved through the Web of Science database as the research object, and the VOSviewer measurement analysis tool is used to analyze the existing international research results. According to the research results, the research on construction waste in the field of construction research has attracted much attention in recent years. At the same time, domestic scholars have made outstanding contributions to this field, but they have the disadvantages of insufficient research depth and low citation rate. The research hotspots in the field of construction waste mainly focus on the construction waste recycling aggregate, construction waste management, and construction waste resource utilization strategy.
\end{abstract}

\section{Introduction}

Construction waste is an important part of municipal solid waste, it is wastes such as spoil and materials generated in the process of new construction, reconstruction, expansion and demolition of buildings, structures, pipe networks,etc.,and the process of house decoration. According to the stage of waste generation, construction waste can be divided into construction waste and demolished construction waste ${ }^{[1]}$. With the development of modern cities, people's requirements for infrastructure construction continue to increase, which has led to the rapid development of the construction industry, as well as the reconstruction of a large number of commercial and residential buildings, the amount of urban construction waste has continued to rise. According to statistics, the newly built building area in China is increasing at a rate of 2 billion square meters each year, and it will reach 30 billion square meters by $2020^{[2-3]}$. The continuous increase of construction waste and improper treatment methods have an irreversible impact on the ecological environment, for example, illegal dumping and landfilling have caused biodiversity and soil loss, and to a certain extent also polluted water resources ${ }^{[4]}$.

In recent years, sustainable development based on green ecology has become an issue of increasing concern worldwide. Scholars are also increasing their research on construction waste, faced with massive research literature from different fields, traditional literature research methods are limited by time and have certain limitations, it is difficult to fully and accurately grasp the overall characteristics, frontier dynamics and evolutionary laws and trends of construction waste research from a large amount of research data. With the rapid development of information visualization technology, scientific knowledge graph analysis has become a new type of data mining and analysis technical method, it takes scientific knowledge as the research object, and directly and clearly expresses the internal knowledge structure and development process of a specific research field through graphical relationships.

Based on the status of publications in the field of architecture in the Web of Science database, this article statistically analyzes the number of publications in the field of architecture at home and abroad in recent years, countries with high production of documents, and research topics, use the bibliometric software VOSviewer to perform visual analysis of author co-occurrence and keyword co-occurrence on the documents in the database. the purpose of the article is to allow scholars in this field to quickly understand and master the development trend of construction waste, and to provide references for the research directions and hot spots of construction waste in my country.

\section{Data sources and research methods}

\subsection{Data Sources}

As the emphasis on the ecological environment has gradually increased in recent years, the research on construction waste is also developing rapidly and widely

\footnotetext{
* Corresponding author E-mail address:442953016@qq.com
} 
used, and related documents are increasing year by year. In order to fully understand the global research status in the field of construction waste, this article intends to collect statistics in the core collection of Web of Science database for nearly 10 years, that is, the documents included in the database from January 2010 to February 2020, the title was set as the search field to conduct a literature search with the keywords "construction waste" and "Construction and demolition waste", after screening, 830 records were finally obtained as research texts, each record contains full-text record information such as the author, publishing organization, abstract, keywords, publication year, issue (volume), and references, and the above information is imported into the VOSviewer software to analyze its research development trend.

\subsection{Research method}

Bibliometric analysis is a method of statistical analysis of documents using the principles of bibliometrics. It mainly analyzes the structure and dynamic aspects of visualized scientific research. Bibliometrics mapping is an important technology in the field of bibliometrics, which can visualize knowledge fields and Relationship between articles, journals, etc ${ }^{[5]}$. This research uses bibliometric diagrams to determine the knowledge fields and research trends of prefabricated buildings based on existing literature.VOSviewer is a free document analysis software, which is widely used in the development of bibliometric drawing.

There are many bibliometric softwares, such as CiteSpace software ${ }^{[6]}$ and CitNetExplorer ${ }^{[7]}$. Compared with these two, VOSviewer can generate distance-based maps to show co-authors, co-occurrence of keywords, citations, bibliographic coupling, and co-citation graphs. And other factors, its biggest advantage is that its visualization effect is better than other bibliometric analysis software. This method has also been widely used in previous literature review studies, so this article uses VOSviewer to analyze and identify the research focus in the field of construction waste, which lays the foundation for the analysis of hot spots in construction waste research.

This paper uses the bibliometric visualization software VOSviewer to analyze the co-occurrence of keywords and authors' co-occurrence in the field of construction waste in various countries in the past 10 years, It provides a reference for relevant researchers in the field of construction waste in china to choose research directions and grasp research hotspots.

\section{Overview of Construction Waste Research}

\subsection{Literature publication year analysis}

According to Fig.1, from the perspective of the distribution of the literature, the research interest in the field of construction waste at home and abroad has continued to rise. The number of articles published in 2020 rose from 28 in 2010 to 173 in 2019 . The reason for the small number of articles published in 2020 is mainly due to the search time when selecting data. But on the whole, the continuous increase in the number of papers published indicates that research in the field of construction waste is becoming a research hotspot for scholars.

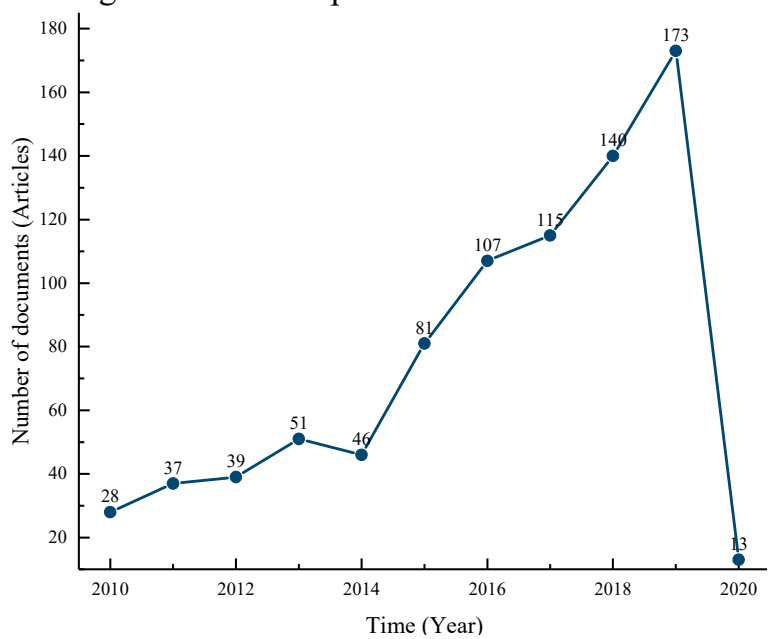

Fig1. Annual papers published in the field of construction waste.

\subsection{Literature publication country analysis}

Import the document records obtained from the Web of Science core collection database into VOSviewer, and set the cooperative relationship analysis unit to the country to draw a country co-occurrence map (Fig.2), a total of 34 key nodes and 98 leads were obtained. According to the color identification of the timeline, my country has conducted extensive research in this field in recent years, and our country has the largest research weight, with a total of 199 articles issued, accounting for $23.98 \%$ of the total number of articles issued. Followed by Brazil (89 articles accounted for $10.73 \%)$, Spain (89 articles accounted for $10.73 \%$ ), Australia (58 articles accounted for $6.99 \%$ ), the United Kingdom (48 articles accounted for $5.78 \%$ ), the United States (39 articles accounted for $4.70 \%$ ).

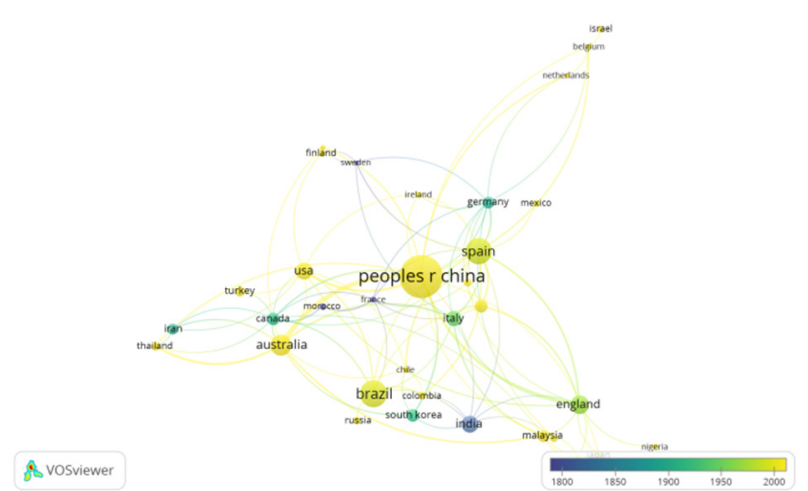

Fig2. National Co-occurrence Map of Construction Waste Research.

\subsection{Representative scholars and articles}

According to the full-text records imported into VOSviewer, set the analysis type to authors under the co- 
authorship menu, And set the minimum number of articles for each author to 3. According to the cluster view (Fig.3), a total of 5 clusters, 21 key nodes, and 128 leads are obtained. In the density view of Fig.4, the color of each key point is determined by the research density of that point. If the research contribution of this point is large, the number of citations will tend to dark yellow, otherwise it will appear blue. Through the density view, the authors of key research in this field can be judged ${ }^{[8]}$. By combining Fig. 3 and Fig. 2 to analyze, among the representative authors in the field of construction waste, Yuan hongping, Zuo jian and Wang jiayuan are cited more frequently, and the co-citation frequency is more than 24. In addition, other authors with higher weights are $\mathrm{Wu}$ huanyu, $\mathrm{Lu}$ weisheng, Zillante george, Poon chi sun, etc.

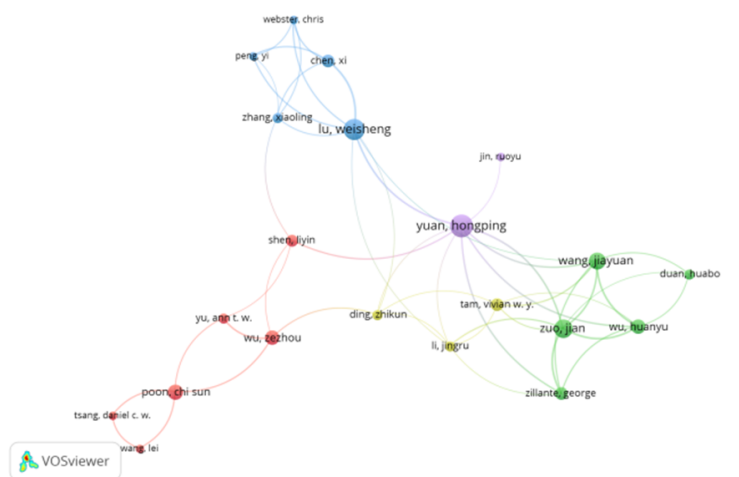

Fig3. Author cluster view of construction waste research.

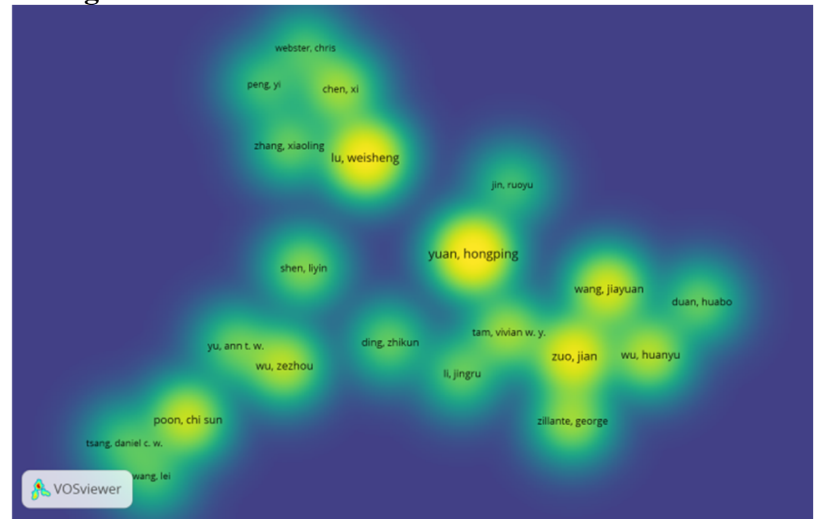

Fig4. Author Density View of Construction Waste Research.

Table 1 shows the information of papers that have been cited more than 100 times in the construction wasterelated articles in the Web of Science core collection database. According to the information in the table, it can be concluded that the research content of highly cited papers mainly involves the following aspects: (1) Application of recycled aggregates: Silva $\mathrm{RV}^{[9]}$ studied the main physical properties and composition of recycled aggregates used in concrete, and carried out statistical analysis on the data in the literature. A performance-based classification for the use of recycled aggregates in concrete construction; Behera $\mathrm{M}^{[10]}$ introduced the production and use of recycled aggregates in concrete, and summarized their influence on the different properties of recycled concrete. The study found that the mechanical properties and durability of recycled concrete are generally lower than conventional concrete, however, recent studies have shown that the mechanical properties and durability of recycled concrete have received increasing attention. (2) Waste management: Yuan, H. ${ }^{[11]}$ through literature research, concluded that the direction of construction waste management is mainly: from the traditional "cost-benefit analysis" to a broader view of sustainability "economy, environment and Social benefits", how to formulate a reasonable construction waste management fee, and how to formulate construction waste management based on the relationship between stakeholders; Yeheyis $\mathrm{M}^{[12]}$ proposed a conceptual construction waste management framework to maximize 3R (reduce, reuse and recycle) and minimize construction by implementing a sustainable and comprehensive strategy throughout the life cycle of a construction project Waste disposal, and establishes life cycle-based sustainability indicators for construction waste, which are used to make decisions related to material selection, classification, recycling/reuse of construction waste, and treatment or disposal options. (3) Use waste to develop sustainable materials: Raut $\mathrm{SP}^{[13]}$ describes various types of waste materials with different compositions, adding them to raw materials in different amounts, developing waste bricks, and studying bricks mixed with different waste materials Various physical, mechanical and thermal properties of the product, put forward application suggestions; Madurwar $\mathrm{MV}^{[14]}$ discussed the potential application of agricultural waste as an alternative to sustainable building materials to reduce the use of natural resources and energy; Bravo $\mathrm{M}^{[15]}$ analyzed the mechanical properties of concrete made from construction waste and recycled aggregates from all over Portugal. It was believed that when excessive recycled aggregates were added, the material properties would be reduced. Therefore, from the perspective of mechanical properties, a reasonable amount was added. This type of aggregate is feasible. (4) Key factors for on-site classification of construction waste: Wang $\mathrm{J}^{[16]}$ adopted CSF methods, pilot studies, questionnaire surveys and face-to-face interviews, and concluded that six key factors are manpower, market for recycled materials, and waste classification capabilities, Management level, site space, construction waste classification equipment.

Table1. Statistics of citation information of construction waste related literature

\begin{tabular}{|c|c|c|c|}
\hline Author & Time & Title & Cited frequency \\
\hline Silva, R. V. & 2014 & $\begin{array}{l}\text { Properties and composition of recycled aggregates from construction and demolition waste suitable for } \\
\text { concrete production }\end{array}$ & 275 \\
\hline Behera, Monalisa & 2014 & $\begin{array}{l}\text { Recycled aggregate from C\&D waste \& its use in concrete - A breakthrough towards sustainability in } \\
\text { construction sector: A review }\end{array}$ & 223 \\
\hline Yuan, Hongping & 2011 & Trend of the research on construction and demolition waste management & 169 \\
\hline Raut, S. P. & 2011 & $\begin{array}{c}\text { Development of sustainable construction material using industrial and agricultural solid waste: A review } \\
\text { of waste-create bricks }\end{array}$ & 139 \\
\hline $\begin{array}{l}\text { Madurwar, } \\
\text { Mangesh V. }\end{array}$ & 2013 & Application of agro-waste for sustainable construction materials: A review & 136 \\
\hline Wang, Jiayuan & 2010 & Critical success factors for on-site sorting of construction waste: A china study & 114 \\
\hline
\end{tabular}


Yeheyis, Muluken $2013 \quad$ An overview of construction and demolition waste management in Canada: a lifecycle analysis approach to sustainability

\section{Construction waste research trends}

\subsection{Research hotspot}

Based on the above analysis, set the data analysis type in the VOSviewer software to all keywords under the cooccurrence menu, and set the minimum frequency of keyword occurrences to 4 , resulting in 5 clusters, 226 There are 7 key nodes and 7813 total leads. Table 2 shows the high-frequency keywords whose key frequency is greater than or equal to 30 times calculated by VOSviewer.

Table2. Keywords for construction waste research.

\begin{tabular}{|c|c|c|c|}
\hline Number & Key words & Frequency & $\begin{array}{c}\text { Co- } \\
\text { occurrence } \\
\text { frequency }\end{array}$ \\
\hline 1 & Management & 130 & 704 \\
\hline 2 & Concrete & 111 & 571 \\
\hline 3 & $\begin{array}{l}\text { Construction and } \\
\text { demolition waste }\end{array}$ & 115 & 567 \\
\hline 4 & Demolition waste & 80 & 467 \\
\hline 5 & Performance & 57 & 357 \\
\hline 6 & Waste management & 58 & 325 \\
\hline 7 & Construction waste & 64 & 305 \\
\hline 8 & Recycling & 56 & 278 \\
\hline 9 & Model & 45 & 275 \\
\hline 10 & Generation & 45 & 267 \\
\hline 11 & behavior & 46 & 261 \\
\hline 12 & $\begin{array}{l}\text { mechanical- } \\
\text { properties }\end{array}$ & 39 & 259 \\
\hline 13 & china & 39 & 256 \\
\hline 14 & fly-ash & 40 & 249 \\
\hline 15 & sustainability & 44 & 233 \\
\hline 16 & strength & 39 & 230 \\
\hline 17 & system & 32 & 211 \\
\hline 18 & cement & 34 & 195 \\
\hline 19 & $\begin{array}{c}\text { Compressive } \\
\text { strength }\end{array}$ & 35 & 189 \\
\hline 20 & aggregate & 32 & 181 \\
\hline
\end{tabular}

The keyword co-occurrence cluster view (Fig.5) and keyword co-occurrence density view (Fig.6) are obtained through keyword cluster analysis. In the cluster view, the same research field is displayed in the same color, and the size of the label indicates the research weight of the item. It can be seen from Fig. 5 that there are 5 different research fields in the scope of construction waste research, combined with the density view to summarize and summarize,the 5 clustering themes are: the application of recycled aggregate(red cluster), construction waste management (Green cluster),construction waste recycling(blue cluster), construction waste resource utilization strategy (yellow cluster), development of recycled aggregate (purple cluster).

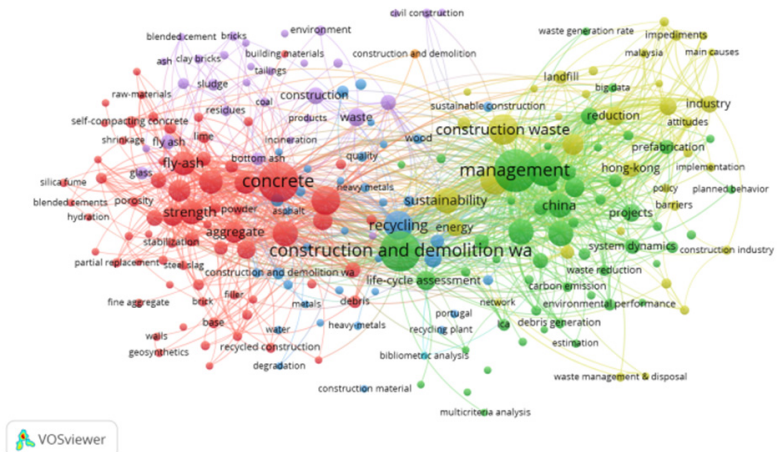

Fig5. Keyword co-occurrence cluster view.

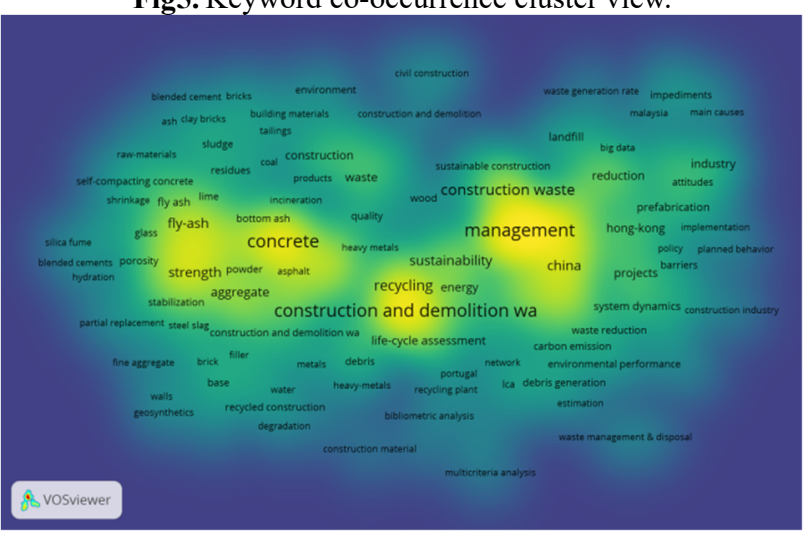

Fig6. Keyword co-occurrence density view.

\subsection{Research areas}

According to the construction waste research timeline in the five clustering themes and keyword co-occurrence tag view (Fig.7), the research fields are summarized as: construction waste recycled aggregate, construction waste management, and construction waste resource utilization strategies.

\subsubsection{Construction waste recycled aggregate}

With the accelerated development of urbanization and infrastructure, the extraction of raw materials required for construction projects has increased, and the demolition of old buildings and municipal facilities has produced a series of construction waste. At present, the domestic treatment and disposal methods of construction waste are mainly open-air stacking and landfilling. A small number of materials used for filling roads and foundations or antifreeze layers are recycled and reused. Construction projects have led to the shortage of natural resources and increasingly serious environmental damage. Therefore, the regeneration of construction waste as a resource is currently a hot area of research at home and abroad ${ }^{[17]}$. 


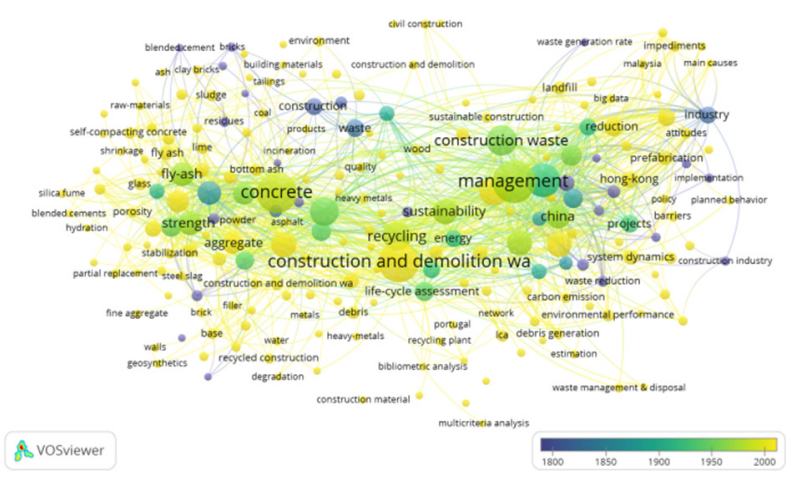

Fig7. Keyword co-occurrence tab view.

In 1946, Russian scientist Glushge proposed the concept of construction waste recycling and studied the basic properties of construction waste recycled concrete $^{[18]}$.In 1977,Japan formulated the specifications for the use of recycled aggregates and recycled concrete. The United States stipulated in the concrete aggregate standard in 1982 that waste concrete can be used as coarse and fine aggregates after treatment.my country only began to use construction waste as a resource in the $1980 \mathrm{~s}^{[3]}$.

The main components of construction waste are waste concrete and masonry, so in recent years, the above two are used as the main preparation materials of recycled aggregates for research at home and abroad. In 2014,Behera $\mathrm{M}^{[10]}$ applied recycled aggregates with different properties to concrete for testing, and found that the mechanical properties and durability of recycled concrete are generally lower than conventional concrete, which provides a way to improve the mechanical properties and durability of recycled concrete in the future. research direction. In 2011, Raut $\mathrm{SP}^{[13]}$ and others developed recycled bricks and stones by adding different amounts of construction waste to raw materials, and put forward corresponding opinions and measures based on different physical and chemical properties.

The development and application of recycled aggregates, on the one hand, solves the difficulty in the treatment of construction waste and the resulting environmental pollution. On the other hand, the reuse of construction waste, screening and re-creating the required construction materials can reduce construction materials consumption, thereby reducing the damage to the ecological environment, and achieving the purpose of protecting the earth's homeland on which mankind depends.

\subsubsection{Construction waste management}

The object of construction waste management is mainly the waste generated during the construction, decoration and demolition of the project, and its purpose is to reduce the generation of construction waste as much as possible at the source.Other construction waste generated is reused or recycled in a specific way ${ }^{[19]}$.

In 1962, American economist Balding proposed the concept of circular economy ${ }^{[20]}$, pointing out that human beings should transform economic activities from the traditional

"resources-products-waste-end management"model to "resources-products-renewable resources".Cycle mode. As a new type of economic production mode, the development principle of circular economy is "reduction, resource utilization, and reuse" to maximize resource utilization, reduce waste discharge as much as possible, and achieve sustainable economic and social development. Therefore, the hierarchical model of construction waste management can be divided into four stages: reduction,reuse,recycling, and disposal of construction waste ${ }^{[11]}$.

In the circular economy 3R (reduce, reuse, recycle) principle, construction waste reduction is the most effective way to manage construction waste, that is, to carry out cleaner production. Using this method can control the amount of construction waste generated from the source comprehensive management of the quantity, volume, type, and harmful substances of construction waste can achieve the dual goals of saving natural resources and reducing pollution ${ }^{[21]}$.

\subsubsection{Resource utilization strategy}

According to the management level of construction waste, at this stage, construction waste management has changed from "end treatment" to "source reduction management off-site management"to realize the entire process of"resource management".In 2012, Yuan $\mathrm{H}^{[22]}$ established a quantitative model of social benefits of construction waste resource management based on system dynamics theory,literature research and questionnaire surveys, and concluded that the resource management of construction waste can increase jobs and improve environmental pollution,Improve social satisfaction and other benefits.

At present, the utilization rate of construction waste in Japan and South Korea has reached over $97 \%$ each year, and over $90 \%$ in EU countries, as a large manufacturing country, China's resource utilization rate is only about $5 \%{ }^{[23]}$, which is far from other countries. It shows that China's construction waste resource utilization in the whole process management not only requires all stakeholders to give full play to their own advantages and capabilities. A systematic and flexible legal guarantee system for the recycling of construction waste is needed to guide the smooth progress of the recycling process of construction waste.

In recent years, various parts of the country have successively introduced construction waste resource management policies, which have put forward clear requirements in terms of source reduction management of construction waste, disposal and disposal fees, etc. Among them, although my country has achieved certain results in the construction waste disposal fee system, the issue of fee collection standards has not yet been resolved. If the fee is too low, producers will give priority to off-site disposal, which is not conducive to resource utilization. Excessive charges will lead to more illegal dumping activities, which will increase environmental pollution. According to the current domestic construction waste fees, it is basically unable to meet the operating costs of recycling, transportation, resource utilization and production, and 
infrastructure costs for treatment and disposal. In addition, when formulating a fee system, the environmental losses caused by the discharge of construction waste should be included. Therefore, the construction waste management departments in various places should hold a seminar on the construction waste treatment charging system in a timely manner to jointly discuss the reasonable construction waste treatment charging standards in the region, the fee collection process, and the usage of the fee. In addition, in order to facilitate the recycling and utilization of construction waste, the construction waste disposal fee system reflects the encouragement of the source classification collection of construction waste. For example, the collection price of mixed construction waste is much higher than that of classified construction waste, thereby stimulating the source classification of construction waste collect.

\section{Conclusion}

This study uses visualization tools to excavate and analyze 830 effective records in the Web of Science core collection database. It is found that the amount of publications in the field of construction waste has increased year by year. And Chinese scholars have made more prominent contributions to this field, and domestic scholars account for a large proportion of core authors in this field. The research hotspots in this field focus on construction waste recycled aggregates, construction waste management, and construction waste resource utilization strategies. Construction waste recycled aggregates and resource utilization strategies are research fields that have gradually emerged in recent years, and there are still many problems to be solved urgently.

\section{Acknowledgements}

This study was supported by the Qinghai Provincial Applied Basic Research Project Fund (Grant No.2018-ZJ734), the National Natural Science Foundation of China (Grant No.71463047), and the Qinghai Provincial Key Laboratory of Energy-saving Building Materials and Engineering Safety (Grant No. 2018-ZJ-T01).

\section{References}

1. GB/T50743-2012. Technical Specification for Recycling of Engineering Construction Waste [S].

2. Tam, V.W., Fung, I.W., Sing, M.C.,et al. J.Cleaner Production,216-231, 109(2015).

3. Zhu Dongfeng. South China University of Technology (2010).

4. L Jaillon, C Poon. Construction Management and Economics, 953-966, 26 (9),(2008).

5. van Eck N, Waltman L. Scientometrics, 523-538. 84(2),(2009).

6. Chen C, Ibekwe SanJuan F, Hou J.Journal of the American Society for information Science and
Technology, 1386-1409, 61(7),(2010).

7. Van Eck N J, Waltman L. Journal of Informetrics, 802-823, 8(4),(2014).

8. Gao Kai. Science and Technology Information Development and Economy, 95-98,12,(2015).

9. Silva R V , De Brito J , Dhir R K .Construction and Building Materials, 201-217, 65,(2014).

10. Behera M,Bhattacharyya S K,Minocha A K,et al. Construction \& Building Materials, 501-516, 68,2014

11. Yuan,H.,Shen,L.WasteManagement,670-679,31(4), (2011).

12. Yeheyis M,Hewage K,Alam $\mathrm{M} S$, et al.Clean technologies and environmental policy,8191,15(1),(2013).

13. Raut S P, Ralegaonkar R V ,Construction \& Building Materials,4037-4042,25(10),(2011).

14. Madurwar M V, Ralegaonkar R V ,Mandavgane S A. Construction \& Building Materials, 872878,38,(2013).

15. Bravo M,Brito J D,Pontes J,et al.Journal of Cleaner Production,59-74,99(1),(2015).

16. Wang J,Yuan H,Kang X,et al.Resources Conservation \& Recycling,931-936,54(11),(2010).

17. Xiong Feng. Chongqing University,(2017).

18. Wang Bo.HuazhongUniversity of Science and Technology,(2012).

19. Wu Zezhou. Chongqing University,(2012).

20. Zhang Jiayi. Bohai University,(2016).

21. Yang Qingdong.Inner Mongolia University of Science and Technology,(2012).

22. Yuan H.Waste Management, 0-1228,32(6),(2012).

23. Qin Yuebo.Nanjing Forestry University,(2009). 